\title{
PERAN KINERJA PERAWAT DALAM PERENCANAAN ASUHAN KEPERAWATAN
}

\author{
Wanda Miftah Fatihah
}

Email : wandamiftah22@gmail.com

\begin{abstract}
ABSTRAK
Asuhan keperawatan adalah suatu proses rangkaian kegiatan untuk pemecahan masalah pada pasien dalam pelayanan keperawatan. Perawat dituntut untuk mengetahui mengenai proses keperawatan sekaligus dapat menerapkan kinerja yang optimal. Kinerja perawat yang belum optimal akan membuat perencanaan asuhan keperawatan klien tidak terpenuhi.
\end{abstract}

Kata Kunci : Asuhan keperawatan, kinerja perawat, pasien.

\begin{abstract}
Nursing care is a process of a series of activities for problem solving in patients in nursing services. Nurses are required to know about the nursing process while also applying optimal performance. The performance of nurses who have not been optimal will make the planning of client nursing care unfulfilled.
\end{abstract}

Keywords : Nursing care, nursing performance, patients. 


\section{Latar Belakang}

Proses keperawatan merupakan suatu metode yang digunakan perawat dalam metode pemecahan masalah yang ada pada klien.

Proses keperawatan merupakan proses yang bersifat ilmiah dan tindakannya untuk mendapati dan mengkaji klien agar dapat membantu klien menuju kesehatan yang optimal.

\section{Menetapkan}

diagnosa, perencanaan yang sistematis, serta melakukan tindakan keperawatan merupakan langkah yang dapat dilakukan agar tercapainya kesehatan klien yang optimal.

Proses pada keperawatan juga harus dilakukan secara terus menerus, dinamis, saling berkaitan, dan secara berurutan (Wolf \& Weitzel).

Namun, masih banyak permasalahan keperawatan yang belum melakukan asuhan keperawatan sesuai dengan Standar Operasional Prosedur (SOP). Beberapa perawat masih melakukan pelayanan kesehatan tidak secara professional

\section{Metode}

Metode yang dilakukan dalam penulisan kajian ini yaitu dengan membaca buku, menganalisis, serta mengeksplorasi dari referensi yang berkaitan dengan " Peran Kinerja Perawat Dalam Perencanaan Asuhan Keperawatan" melalui referensi yang berbeda, yaitu beberapa ejournal, text book, tesis, yang didapat kan dengan memuat google scholar, dengan memasukan kata kunci sesuai judul kajian.

\section{Hasil}

Berdasarkan kajian yang sudah dilakukan mengenai "Peran Kinerja Perawat Dalam Perencanaan Asuhan Keperawatan", dari beberapa referensi mendapatkan hasil bahwa perawat yang memiliki kinerja baik dan pengalaman yang banyak akan lebih menerapkan proses keperawatan sesuai standar dapat menjamin setiap orang yang berkunjung di Rumah sakit. 
Pembahasan

Asuhan keperawatan adalah suatu proses rangkaian kegiatan untuk pemecahan masalah pada pasien dalam pelayanan keperawatan. Kegiatan ini dilakukan tenaga keperawatan yang memiliki wewenang dalam menjalankan profesi.

Perawat yang melaksanakan asuhan keperawatan diharapkan untuk memiliki beberapa kemahiran, antara lain :

1. Menetapkan diagnosis keperawatan

2. Dapat berkomunikasi dengan baik dengan tenaga kesehatan lain, klien maupun keluarga klien.

3. Dapat menginterprertasikan hasil pemeriksaan penunjang yang telah dilakukan.

4. Dapat mengkaji kondisi klien.

5. Mampu mengevaluasi tindakan keperawatan yang telah dilakukan pada klien sesuai kebutuhan klien.

Kinerja perawat merupakan beberapa pencatatan dari hasil yang sudah tercapai secara optimal oleh tenaga kesehatan keperawatan dengan legal (tidak melanggar hukum), sesuai dengan wewenang dan sesuai dengan etika dan moral (Nawawi,2013).

Untuk mengetahui mengenai pencapaian hasil kerja perlunya dilakukan penilaian kerja. Kegiatan penilaian kerja dapat membantu manajer dalam pengambilan keputusan atau umpan balik pada perawat mengenai pelaksanaan pekerjaan yang telah dilakukannya.

Ada beberapa komponen kinerja yang dinilai penting, antara lain:

1. Kerjasama yang dilakukan dengan orang lain saat melakukan kegiatan atau tugas yang sudah ditentukan.

2. Beban kerja yang sudah diberikan pada perawat

3. Ketaatan atau kedisiplinan perawat dalam peraturan yang sudah ditetapkan.

4. Tanggung jawab perawat atau kesanggupan perawat dalam melakukan pekerjaan yang telah diberikan dengan optimal. 
Ada beberapa faktor yang yang mempengaruhi kinerja, antara lain faktor individu, faktor organisasi, dan faktor psikologi (Gibson, 2001).

\section{Faktor Psikologi}

Contohnya motivasi, merupakan sebuah interaksi seseorang dengan situasi tertentu dan memberikan dorongan untuk mencapai tujuan tertentu yang diinginkan (Suarli \& Yayan, 2008).

\section{Faktor Organisasi}

contohnya supervisi merupakan pengamatan secara langsung oleh atasan pada pekerjaan yang sedang atau telah dilakukan bawahan, apabila ditemukan masalah segera diberikan solusi guna mengatasinya (Suarli \& Yayan, 2008)

Adapula beberapa karakteristik perawat yang terkait kinerja, antara lain :

1. Umur

Perawat usia produktif yang masih memerlukan bimbingan dan arahan dalam bersikap disiplin dan rasa tanggung jawab di usia produktif biasanya lebih maksimal.
2. Tingkat Pendidikan

Tingkat pendidikan perawat di masih perlu ditingkatkan dalam melakukan pendokumentasian asuhan keperawatan.

3. Pelatihan

$\begin{array}{ccc}\text { Pelatihan } & \text { berfungsi } & \text { untuk } \\ \text { memanajemen } & \text { yang } & \text { perlu }\end{array}$
dilaksanakan terus menerus dan ini sangat penting dalam peningkatan kualitas dokumentasi asuhan keperawatan.

Rumah sakit merupakan suatu pelayanan kesehatan yang diberikan dari beberapa tenaga kesehatan pada klien/pasien, terutama pada tenaga keperawatan.

Tim tenaga keperawatan merupakan garda terdepan yang 24 jam menghadapi masalah yanhg dialami oleh klien. Perawat harus senantiasa memberikan pelayanan yang optimal dan memenuhi kebutuhan klien.

Peningkatan kinerja perawat akan mengikuti peningkatan proses keperawatan. Jika proses keperawatan dilakukan secara baik dan sistematis 
kualiyas pelayanan keperawatan di rumah sakit akan berjalan dengan baik.

Perawat juga dapat mengembangkan kemampuannya agar pasien senang dan puas dengan pelayanan yang di lakukan pada proses keperawatan.

\section{Penutup}

\section{Kesimpulan}

Perawat professional harus memiliki kinerja yang baik, serta mampu melakukan tindakan keperawatan secara optimal dan tidak melanggar kode etik, dan hukum. Jika perawat memiliki kinerja yang baik dalam pemenuhan kebutuhan klien, kualitas pelayanan dirumah sakit akan berjalan dengan baik.

\section{Daftar Pustaka}

Aini, N. (2018). Model Keperawatan beserta aplikasinya dalam keperawatan. UMM PRESS. Universitas Muhammadiyah Malang

Astar, F. Tamsa, H. \& Kadir, I. Pengaruh Pelayanan Asuhan Keperawatan Terhadap Kepuasan Pasien Di Puskesmas Takalala Kabupaten
Soppeng. Journal of management. 1(2). $33-57$

Butar-Butar, J., \& Simamora, R. H. (2016). Hubungan Mutu Pelayanan Keperawatan dengan Tingkat Kepuasan Pasien Rawat Inap di RSUD Pandan Kabupaten Tapanuli Tengah. Jurnal Ners Indonesia, 6(1), 50-63.

Carpenito, L.J., (1999). Rencana Asuhan dan Dokumentasi Keperawatan, Diagnosa Keperawatan dan Masalah Kolaboratif Edisi 2. Jakarta: EGC.

Dermawan,D. (2012). Proses Keperawatan Penerapan Konsep dan Kerangka Kerja (1st ed.). Yogyakarta: Gosyen Publishing

Doengos, M.E., (2000), Rencana Asuhan Keperawatan : Pedoman Untuk Perencanaan Pendokumentasian Perawatan Pasien Ed. 3

Efendi, N. F. (2015). Pendidikan dalam keperawatan. Surabaya: Salemba Medika

Eriyani. (2020). Dokumentasi Keperawatan. Medan Estate: Sekolah Tinggi Ilmu Kesehatan Binalita Sudama Medan 
Mugianti, S. (2016). Manajemen Kepemimpinan dalam Praktek Keperawatan. Modul Bahan Ajar Cetak Keperawatan

Nursalam. (2014). Manajemen

Keperawatan: Aplikasi dalam Praktik Keperawatan Profesional. Jakarta: Salemba Medika

Simamora, R. H. (2005). Hubungan Persepsi Perawat Pelaksana Terhadap Penerapan Fungsi Pengorganisasian Yang Dilakukan Oleh Kepala Ruangan Dengan Kinerjanya Diruang Rawat Inap RSUD Koja Jakarta Utara (Doctoral dissertation, Tesis FIK UI, Tidak dipublikasikan).

Supratti . Ashriady . (2016). Pendokumentasian Standar Asuhan Keperawatan Di Rumah Sakit Umum Daerah Mamuju, Indonesia. Jurnal Kesehatan MANARANG . 2(1). 44-51

Terok, M., Sumarauw, H ., Onseng,S.L., (2015). Hubungan Kinerja Perawat Pelaksana Dengan Penerapan Proses Keperawatan Di Irina C Blu RSUP Prof Dr.R.D.Kandou Manado. JUIPERDO. 4(1). 55-56
Utami, N. W . dkk. (2016). Etika Keperawatan dan Keperawatan Profesional. Modul Bahan Ajar Cetak Keperawatan 